\title{
Proposal Hardware and Software Modules for Multi-agent System of Robosoccer
}

\author{
Marek Sukop, Mikuláš Hajduk, Jozef Varga* \\ Technical university of Kosice, Faculty of mechanical engineering, Department of Robotics, Němcovej 32, 04200 Košice, Slovak Republic
}

\section{BIOGRAPHICAL NOTES}

Marek Sukop, doc. Ing., PhD., born in October 2, 1976 in Košice, is associated professor of Department of Robotics, Faculty of Mechanical Engineering, Technical University of Košice. He is graduated on Faculty of Mechanical Engineering, TU in Košice, where he received also scientific degree PhD and where be habilitated at the field of production systems. He has expertise in the solution of projects focusing on industrial robotics, cooperation multirobotic industrial robots, utilizing the peripheral devices on robotics workplaces. He is world champion in robotic football of 2010 under the auspices of an international organization FIRA.

Jozef Varga, Ing, PhD., born in January 28, 1986 in Trebišov, is assistant of Department of Robotics, Faculty of Mechanical Engineering, TU in Košice. He graduates in 2010 at a Technical university of Košice, Faculty of Mechanical Engineering, Department of production Systems and Robotics, where he received also scientific degree PhD. Currently he Works on the field of design of robotic systems and all it's components.

Mikuláš Hajduk, prof. Ing., PhD., born in December 12, 1950, Malé Ozorovce. He graduates as professor in 1999 at Technical University of Košice in the filed of "production systems with industrial robots and manipulators". Nowadays he is the head at department of production systems and robotics and also an authorized person for robotic and production techniques. He is chairman and also member of board of state examiners. His scientific and research work focuses on the field of research and development of production systems and robotics. An accent is put on the issue of designing and maintenance of automatic robotic systems based on method implementation of computer intelligence.

\section{KEY WORDS}

Agent, multi-agent system, mobile robot, robosoccer.

\section{ABSTRACT}

This article describes the implementation of the basic hardware and software modules used by FME TU Robotics team in international competitions in the robotic soccer (category Mirosot).

\section{Introduction}

Proposal so complex autonomous robotic multi-agent systems, such as robotic soccer is composed of solving of several hardware components and software elements also to ensure proper operation of the hardware. Particularly in the initial proposal was necessary based on the options that are bounded by FIRA rules [7]. Field has dimensions of $1.8 \times 2.2 \mathrm{~m}$. Goals are $40 \mathrm{~cm}$ wide. Each robot can have a maximum size such that went into cubes of side $7.5 \mathrm{~cm}$. For the uninitiated viewer are all very similar 
teams with minimal differences. A closer perusal in the implementation of system components shows that each team has its own unique philosophy approach to system design. FME TU Robotics team also approached to develop unique, which was based on the general arrangement system of the rules (Fig.1).

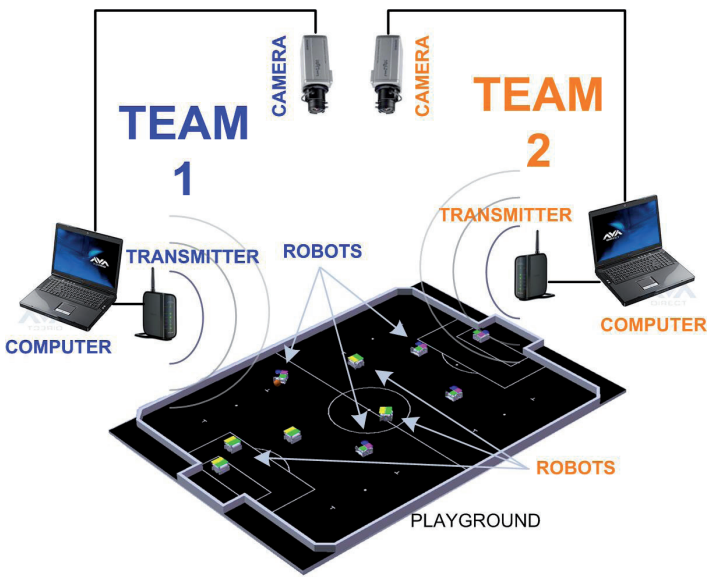

Fig. 1: Arrangement of components in robotic football for category Mirosot.

\section{The main control loop}

Basic tasks before proposing the arrangement of modules in the system was to determine the course of the processes in the management system of. The entire control loop (Fig. 2) is based also on the options that are given rules.

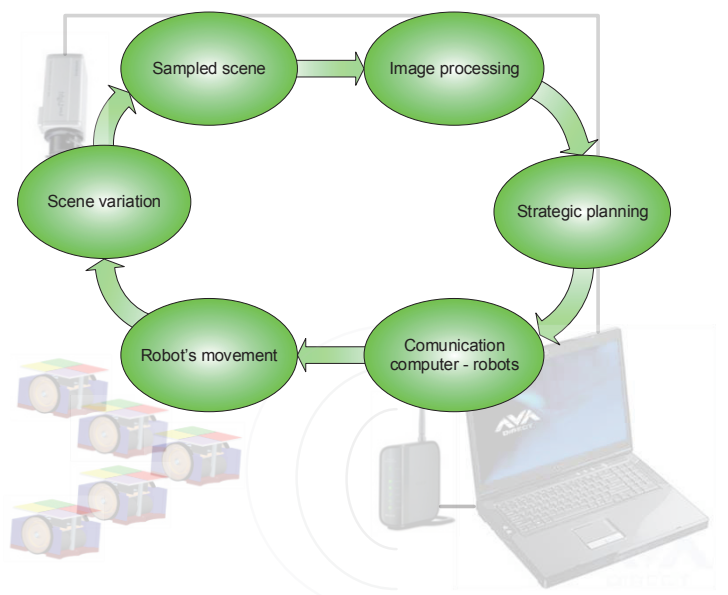

Fig. 2: Progress of processes in main control loop robotic soccer.

Camera frame rate indicates the number of traces loops per unit of time. A prerequisite, however, is that the time between two frames is sufficient for the rest of the acts in the loop.

\section{Arrangement of modules in the robot soccer system}

In the course of the arrangement of the modules were only slightly modified, and the final form which is used in the arrangement currently on Figure 3, where the modules are rounded hardware blocks and software modules are in the blocks with sharp edges.

At the beginning of the string module (Fig. 3) is a camera. The image is via IEEE 1394 (FireWire) transmitted to the control computer. The results of image processing are positional parameters robots and the ball. All these parameters are stored in memory (last 67 frames $=1$ second frame rate of 66.6). This memory is then available agent Master (software agent) and elemental players' agents (those agents after assigning the robot consists of players' agents). Master agent uses this memory to estimate the ball motion and the opponent motion under which continuously collected from the defined strategic actions. According to the chosen strategic actions taken up in 5 elementary players' agents who were in the development phase of an overall strategy assigned to each strategic action. Finally assigns elementary agent of one of the robots (ID), hence the complex agent player is able to influence events on the playing field. Master agent decides on the selection of strategic actions, and the selection of elementary players' agents according to user- selected overall strategy. Elemental players' agents have all the necessary information about the location of all the entities on the game field. From this information to plan their movement, so to get the ball into the opponent's goal, respectively, to prevent an opponent score. Once you have planned your move transmit this information to a software module that ensures communication. After adjusting the data and pairing it with robots will transfer them to a USB port in the module for transforming the RS485 interface. Mentioned software portion occurring in the control computer are shown in Figure 4.

For each robot was used transmitter with its own specific channel to transfer information wirelessly. The data is then parallel to each robot sent cyclically until there is no new data being recorded. Said concatenation 5 transmitters on the bus we were 


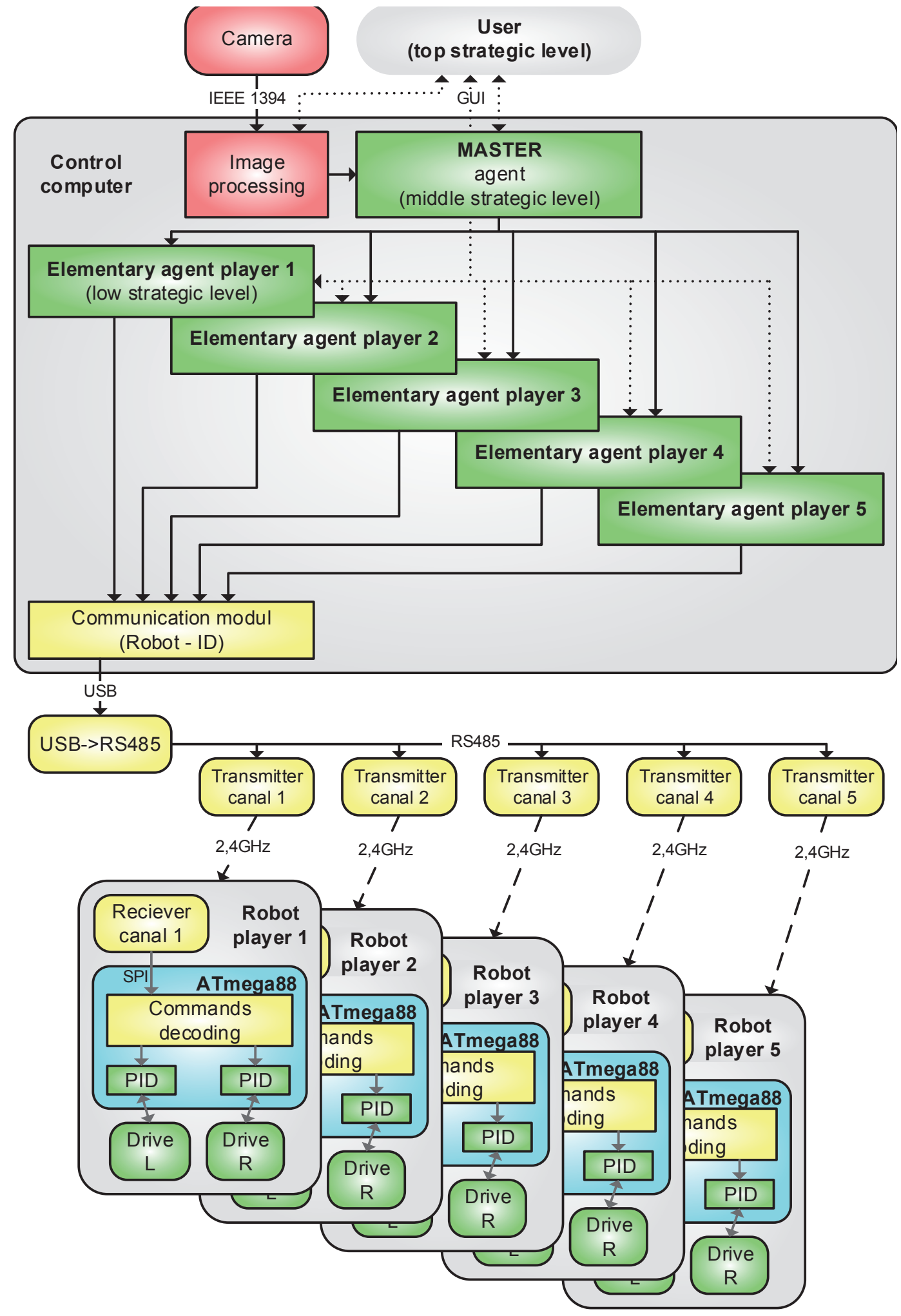

Fig. 3: Arrangement of modules in the system (rounded edges - hardware modules, sharp edges - software modules). 


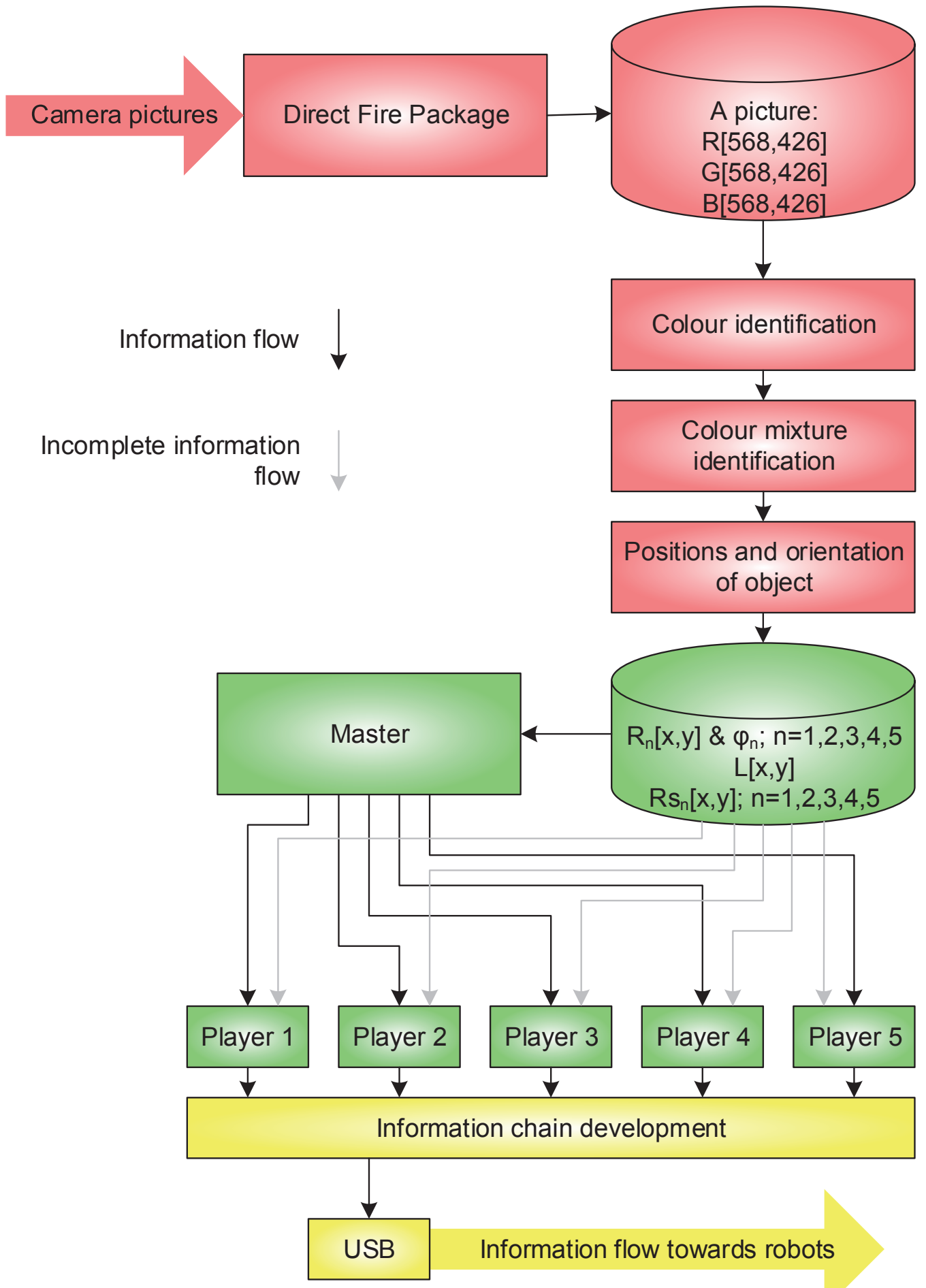

Fig. 4: The main part of the software in the control computer (image processing - the red, the strategic behavior of the system of - green color, communication with robots - yellow). 
the first in the world used in the category Mirosot. Due to the fact that each transmitter has the possibility to change to one of 96 channels, there is no breach of the rules for broadcasting. Robot after the capture of the transmitted data packet changes its parameters at the desired speed, as fast as possible. This will change the scene for the next recorded image.

\section{Robot as a player (design, electronics, soft- ware)}

Basic mechanical parts, the mechanical structure consists are: chassis, trucks, wheels, bearings and gears. In the course of the used already possesses the fourth generation chassis, which is a fourwheeled (Fig.5). Gait parameters are: maximum acceleration of $12 \mathrm{~m} / \mathrm{s}$, maximum speed of $3.5 \mathrm{~m} / \mathrm{s}$ (under optimal conditions). The robot is designed so that it can hold the ball well when cornering, which is used to remove the chassis side panels and center console [6].

Proposal electronic part depends on the requirements for ease while maintaining one level DPS. Block diagram of the electronic hardware with power and signals is shown in Figure 6.

The proposal was the minimum external components outside the microcontroller. Brained ro-

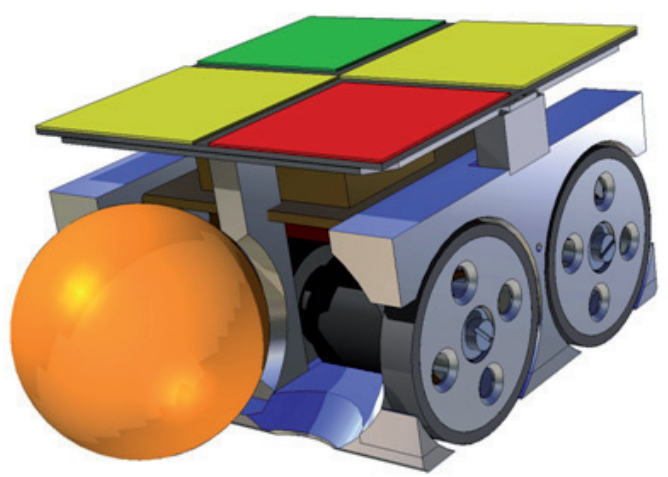

Fig. 5: The latest generation of robot player.

bot ATmega88-16AU overclocked at $22.11 \mathrm{MHz}$, so to be able to perform basic tasks, which are: communication with the module via SPI $5 \mathrm{MHz}$, pulse counting and determining the sequence of pulses from the encoders, software PSD controller with $1 \mathrm{~ms}$ sampling, PWM drives, transforming the speed and angular speed to the desired speed wheel control power. Microcontroller used for the experimental tests, and using a clock frequency showed deficits in communication via SPI receiver unit, which has a supply voltage of $3.3 \mathrm{~V}$. The final draft of the bilayer circuit board (PCB) is on Figure 7.

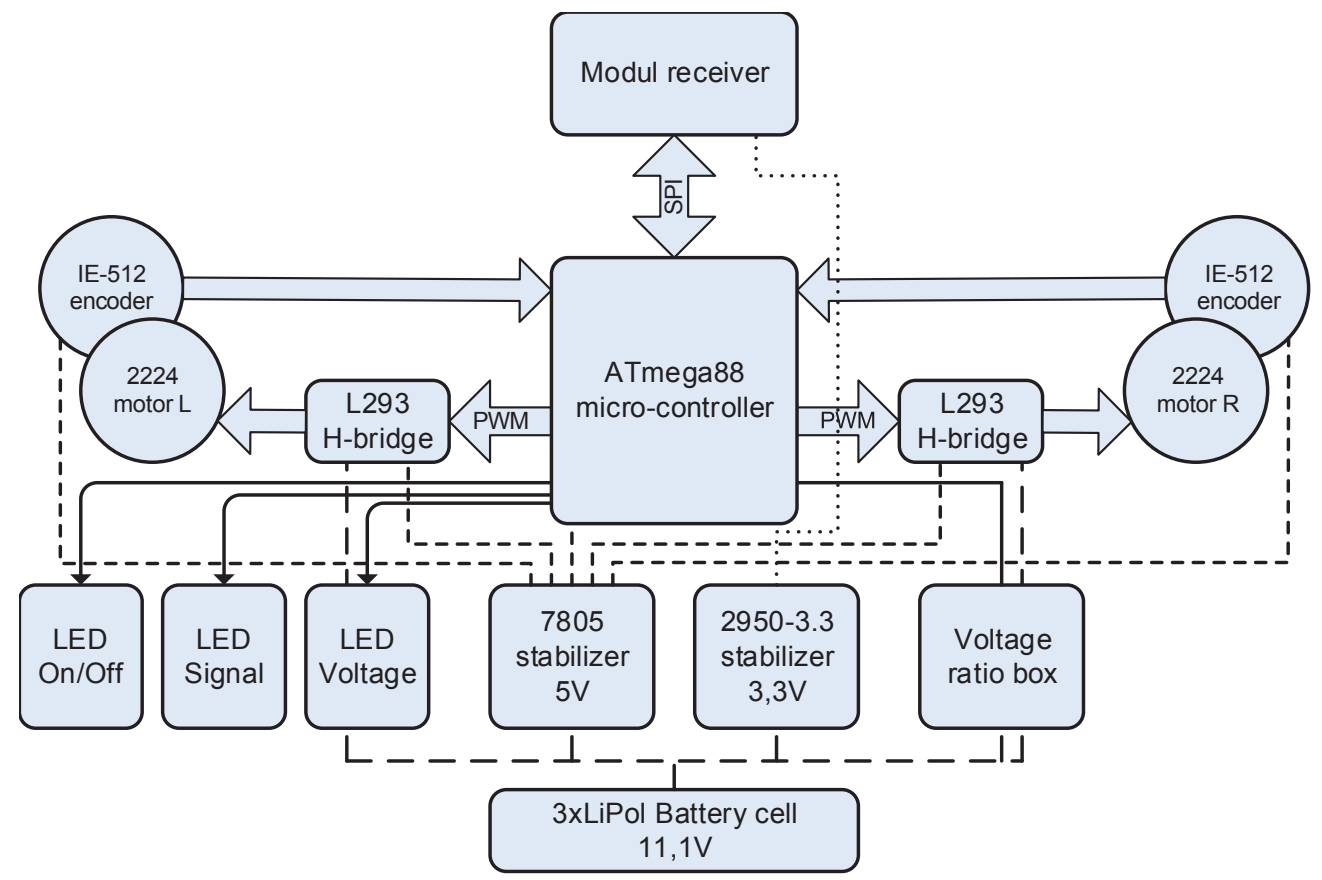

Fig. 6: Block diagram of the electronic robot part. 


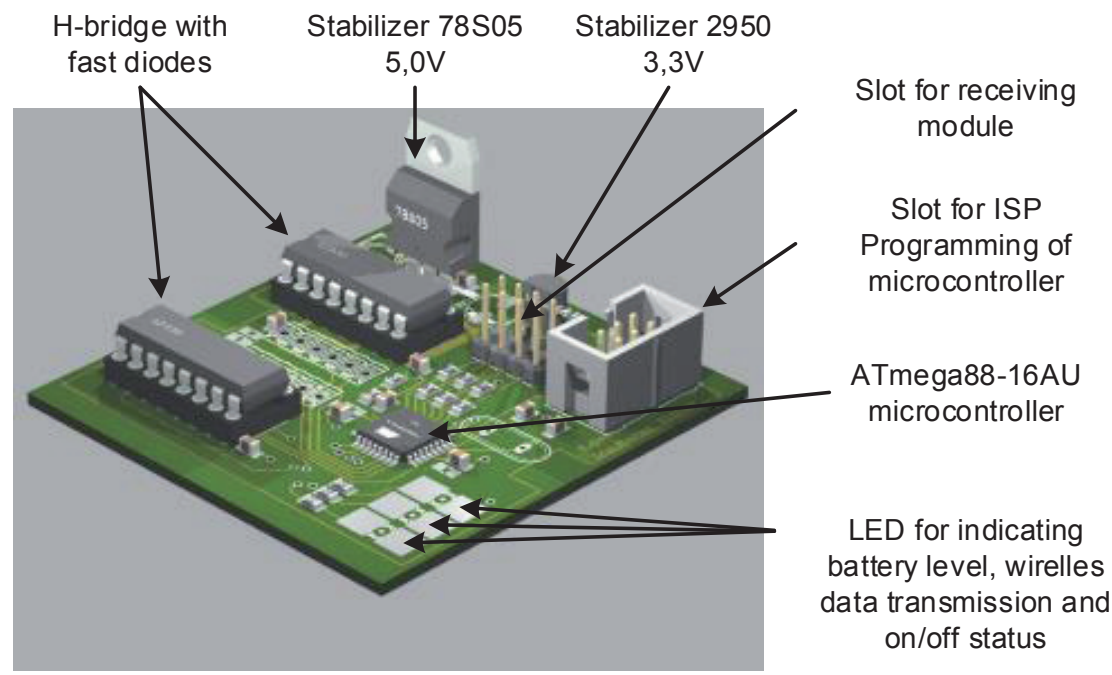

Fig. 7: Printed circuit board robot.

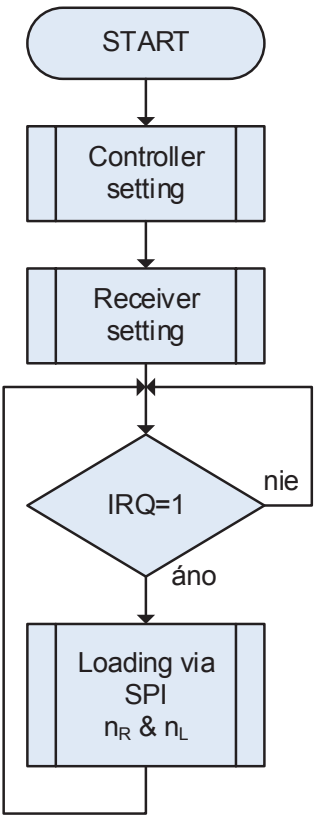

a)

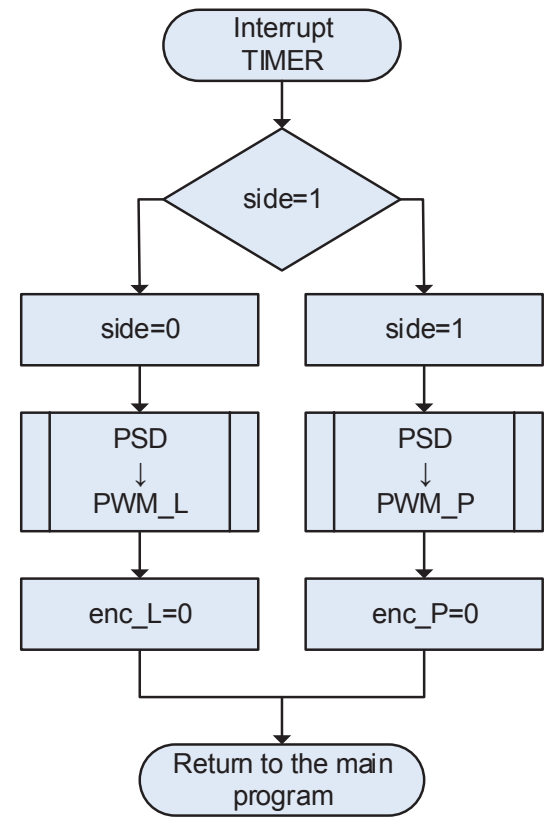

b)

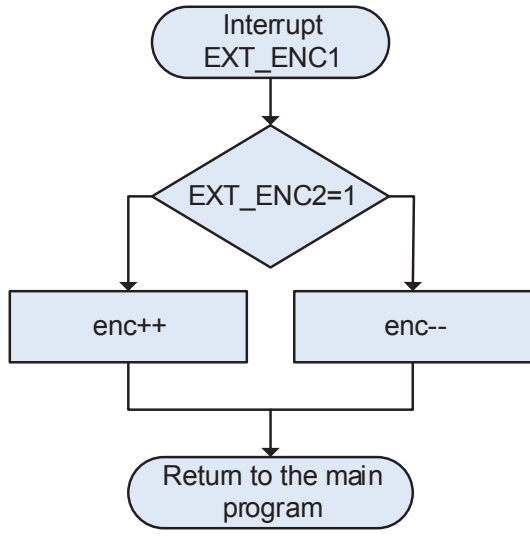

Fig. 8: Flowchart software of the robot.

Simplified flowchart software performing the drive control and communication with the module is in Figure 8.

The body of the main program (Fig. 8-a) initialization of microcontroller begins. Set the inputs, outputs, interrupts, PWM, SPI. Followed by cyclic tracking IRQ flag that is set from the moment the data. After retrieving the data is cyclically repeated again waiting to receive data. Interruption from the leading edge of the output of the encoder (Fig. 8-c) has the same course for both encoders (right and left). After the occurrence of interruption is controlled by the second encoder output (EXT_ENC2). According to the state, the number of pulses, indicating the speed and direction of rotation of the motor, or incremented. decremented. Interrupt timer 
(Fig. 8-b) occur every 500us. At the beginning of a page using a variable separate calculation PSD to right and left engine. Sampling rate for both PSD control is $1 \mathrm{~ms}$, and their operation is phase shifted by $180^{\circ}$.

\section{Conclusion}

The proposed system during the development of several modified and described themselves using the latest version was recorded victory in the World Cup FIRA 2010 Indian Bangalore. View of the control loop is for all teams participating in competitions around the same. But there is a lot of detail about the software and hardware solutions that are unique and distinctive in each team.

\section{References}

[1] HAJDUK, M.SUKOP, M.: Multiagents system with dynamic box change for MiroSot. In: Progress in Robotics: Communications in Computer and Information Science 44. - Berlin: Springer-Verlag, 2009, p.287-292, ISBN 978-3-642-03985-0, ISSN 1865-0929, 2009

[2] KIM,J.H.,Vadakkepat,P.: Multi-agent systems:A survey from the robot soccer perspective Int..J.Intelligent Automation and Soft Computing 6(1), 3-17, 2000

[3] JESSE,N.: Autonomous Mobile Robots-From Science Fiction to Reality. Studies in Fuzziness and SOFT computing, Springer, Heidelberg, 2005

[4] SUKOP, M., HAJDUK, M., VARGA, J.: Aplikácia robotického futbalu: 1. Použité softvérové a hardvérové moduly. ATP, 2013.

[5] SUKOP, M., VARGA, J., JÁNOŠ, R., SVETLÍK, J.: Aplikácia robotického futbalu: 2. Robot ako hráč. ATP, 2013.

[6] SUKOP, M., PÁCHNIKOVÁ, L.: Aplikácia robotického futbalu: 3. Spracovanie obrazu a detekcia robotov. ATP, 2013

[7] SUKOP, M.: Aplikácia robotického futbalu: 4. Modul stratégií. ATP, 2013.

[8] SVETLÍK, J.: Konštrukčné detaily robotického futbalistu 1. 2011, Transfer inovácií. č.19, s.87-90, ISSN 1337-7094, 2011.

[9] KOPÁČEK,P:: Robotsoccer: Post-Present-Future. In: CIRAS 2008, Linz.

[10] http://www.fira.net

[11] http://www.robosoccer.sk

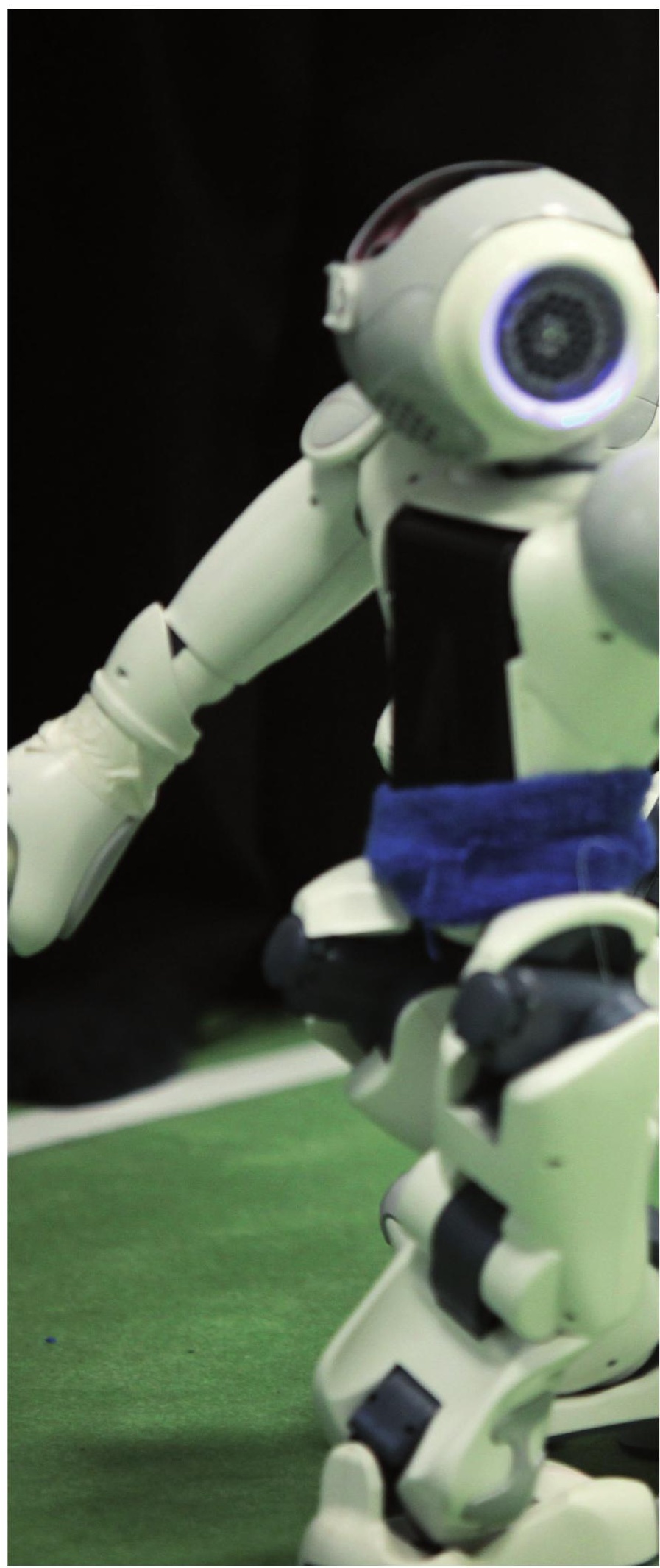




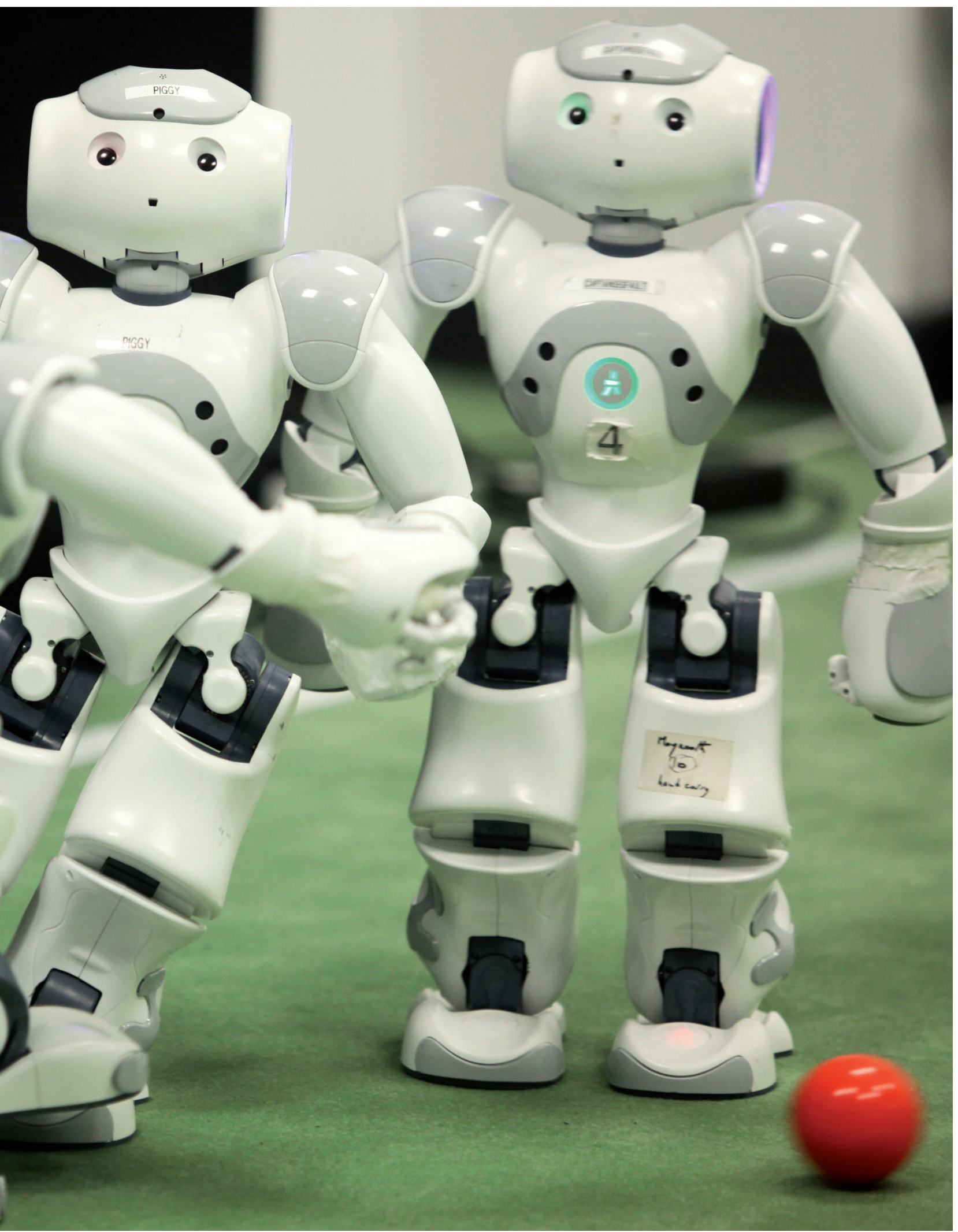

